\title{
EL MATRIMONIO SEGÚN LA BIBLIA
}

\section{Vidal Rivera SABATÉS}

Profesor Contratado Doctor Departamento de Derecho Civil Facultad de Derecho de la UCM vrivera@der.ucm.es

\begin{abstract}
RESUMEN
Identificación y comentario de las principales referencias biblicas sobre el contrato matrimonial judio, donde se analizan sus fases y la eventual disolubilidad del vínculo creado. La visión hebrea del núcleo familiar, las relaciones paterno-filiales y el importante papel atribuido a la primogenitura. Alusión a la singular figura del levirato.
\end{abstract}

Palabras clave: matrimonio, esponsales, repudio, familia, levirato.

\section{ABSTRACT}

Identification and review of the major biblical references on the Jewish marriage contract, which examines the phases and the eventual dissolubility of any bond created. The Hebrew vision of the family unit, parent-child relationships and the important role attributed to the primogeniture. A reference to the singular figure of the levirate.

Keywords: marriage, betrothal, repudiation, family, levirate.

\section{ZUSAMMENFASSUNG}

Es werden die bedeutsamsten Bibelstellen genannt und kommentiert, in denen der jüdische Ehevertrag erwähnt wird. Es werden die Phasen und die mögliche Auflösung dieser ehelichen Verbindung untersucht. Ferner nimmt der Artikel Bezug auf die hebräische Sicht des Familienkerns, die Beziebungen der Eltern zu den Kindern sowie die wichtige Rolle der Erstgeborenenschaft. Ebenso wird auf die besondere Rechtsform der Leviratsehe eingegangen.

Schlüsselwörter: ehe, brautgaben, verstoßen der Braut, familie, leviratsehe. 
En el Antiguo Testamento el matrimonio aparece originariamente como una relación normal —ligada a la más íntima condición del ser humano ${ }^{1}$ - dispuesta por Yahvé, propia de un periodo de inocencia y desbordante alegría; una etapa jubilosa que, con el transcurso del tiempo, daría paso a otra de «dureza de corazón» (Mateo 19, 8), en la que se hicieron indispensables las reglas.

El Génesis $(1,28)$ establece que la función del matrimonio debe ser la fecundidad, el medio de asegurar la descendencia: «Procread y multiplicaos, y henchid la tierra; sometedla y dominad sobre los peces del mar, sobre las aves del cielo y sobre los ganados y sobre todo cuanto vive y se mueve sobre la tierra» ${ }^{2}$. Por esta razón, en el ámbito bíblico, mientras la esterilidad era vista como la peor de las desgracias que podía sufrir una mujer hebrea (1 Samuel 1, 10 ss.) -fruto de un severo castigo de los cielos (Génesis 20,18) - , los hijos abundantes se interpretaban como un signo de bendición ${ }^{3}$ y favor divinos (Salmos 127, 5). Y si el hijo era varón, amén de perpetuarse la línea familiar, el muchacho asumía, llegado el momento, el oficio del progenitor, de manera que se garantizaba la futura prosperidad del linaje.

El contrato matrimonial judío constaba de dos fases. La primera de ellas comenzaba cuando las familias de los futuros esposos (el varón desde que cumpliera los trece años, la mujer desde los doce ${ }^{4}$ ) negociaban ${ }^{5}$ los esponsales de éstos ${ }^{6}$. Constituían los mismos un compromiso más solemne

${ }^{1}$ Con el valor y sentido más profundo del amor y de la vida. Cfr. A. SARmiento, voz «Matrimonio», en C. IzQuierdo (dir.), Diccionario de teología, 1. ${ }^{a}$ ed., Eunsa, Barañáin (Navarra), septiembre de 2006, p. 630.

${ }^{2}$ Las citas bíblicas están tomadas de la Sagrada Biblia, versión directa de las lenguas originales por E. NÁcar Fuster y A. Colunga Cueto, 43. ${ }^{a}$ ed., BAC, Madrid, 1983, p. 4.

${ }^{3}$ Un premio, la mayor gracia de Dios. Cfr. J. Arias, El gran secreto de Jesús, 1. ${ }^{a}$ ed., Aguilar, Madrid, marzo de 2010, p. 131.

${ }^{4}$ Cfr. A. Millard, et al., voz «Matrimonio», Diccionario Bíblico abreviado, C. Ruiz-Garrido (trad.), 3. a ed., Editorial Verbo Divino-Ediciones Paulinas, Estella (Navarra)-Madrid, 1993 , p. 213.

5 El hecho de que los padres concertaran los matrimonios de los hijos no significaba que no se contase nunca con la opinión de éstos. Así, Siquem (Génesis 34, 4) y Sansón (Jueces 14,2) pidieron a sus respectivos padres (Jamor y Manué) que concertasen el matrimonio con las mujeres que uno y otro querían. Cfr. A. Millard, et al., voz «Matrimonio», op. cit., p. 213.

${ }^{6}$ Las relaciones familiares eran algo prioritario para los hebreos. Los componentes de la misma tribu se sentían orgullosos de proceder de un antepasado común y las esposas se tomaban de entre la propia parentela (cfr. Génesis 24, 38 ss.). Sin embargo, la ley prohibía el matrimonio entre parientes próximos (Levítico 18, 6 ss.). Vid. W. R. F. BRowning, voz «Pariente», Diccionario de la Biblia. Guía básica sobre los temas, personajes y lugares bíblicos, J. P. Tosaus Abadía (trad.), Folio, Barcelona, 2006, p. 349. 
y vinculante que nuestra actual petición de $\operatorname{mano}^{7}$, y se suscribían en presencia de dos testigos ${ }^{8}$. Algunas veces, la pareja se regalaba recíprocamente en este acto un anillo o un brazalete?

$\mathrm{Al}$ padre de la joven se le tenía que abonar cierta cantidad de dinero (mobar), el «precio de la esposa». Tal suma podía en ocasiones satisfacerse parcialmente con el trabajo personal del muchacho. Aunque al padre de la novia no se le permitía tocar dicha suma, sí le era dado beneficiarse de los intereses que produjese la misma ${ }^{10}$. Aquella cantidad pasaba a manos de la hija cuando fallecían sus padres, o bien si su marido moría. Labán, suegro de Jacob, infringió esta costumbre y gastó el mohar correspondiente a su hija (Génesis 31, 15).

El padre de la muchacha, a su vez, entregaba a ésta o a su marido una «dote» (u obsequio de casamiento), que podía comprender criados o siervos (como aconteció en los connubios de Rebeca y Lía, cfr. Génesis 29, 24 y 29), tierras u otros bienes ${ }^{11}$.

La segunda fase, la boda, luego de la cual se iniciaba la convivencia, tenía lugar un año después del desposorio, cuando el novio ${ }^{12}$, acompañado de sus amigos, se encaminaba al atardecer a la casa de la novia, quien le aguardaba, luciendo algunos adornos ${ }^{13}$ y finos ornamentos ${ }^{14}$, tocada con un velo ${ }^{15}$ (Génesis 24, 64-67 ${ }^{16}$; Cantar de los Cantares 6, 7). En una

7 Suponían tales esponsales (o promesa) un auténtico acto de matrimonio, incluso jurídicamente. Cfr. R. BerEtTA y E. Broli, Enigmas de la Biblia al descubierto, G. Saloni (trad.), Planeta, Barcelona, 2004, p. 156. Vid. también W. R. F. Browning, voz «Matrimonio», op. cit., pp. 304 y 305. Cfr., asimismo, los arts. 42 y 43 del Código Civil español.

${ }^{8}$ Cfr. A. Millard et al., voz «Matrimonio», op. cit., p. 213.

9 Durante el tiempo de espera hasta el día de la boda, mientras la muchacha vivía todavía en el hogar paterno, se dispensaba al novio de ir a la guerra (cfr. Deuteronomio 20,7).

${ }^{10}$ Cfr. A. Millard et al., voz «Matrimonio», op. cit., p. 213.

${ }^{11}$ Ibid.

${ }_{12}$ Que ya tenía preparado el hogar conyugal.

13 Estos adornos consistían en collares, brazaletes, broches, anillos y ajorcas. Cfr. Isaías 3, 16. Por otro lado, a los israelitas les estaba mandado llevar flecos —orla o borlasen el borde de sus mantos y atar los flecos de cada borde con un cordón de color de jacinto (Números 15, 38). En los Evangelios se destaca la presencia de tales flecos en el manto de Jesús (Marcos 6, 56; Mateo 9, 20; Lucas 8, 44). Cfr. J. Klausner, Jesús de Nazaret. Su vida, su época, sus enseñanzas, J. Piatigorsky (trad.), 1. a ed., Paidós Ibérica, Barcelona, 2006, p. 464 , nota 7.

${ }^{14}$ En Ezequiel $(16,10)$ se menciona un vestido de recamado, piel de tejón, lino fino y seda.

15 Algunas veces, la novia también se engalanaba la cabeza con una cinta con monedas, regalo del novio. Quizá se refiera a una de esas monedas la parábola de Jesús sobre el dracma perdido. Cfr. Lucas 15, 8. Vid. A. Millard et al., voz «Matrimonio», op. cit., p. 213.

16 «También Rebeca alzó sus ojos, y viendo a Isaac se apeó del camello y preguntó al siervo: “¿Quién es aquel hombre que viene por el campo a nuestro encuentro?”. El siervo 
ceremonia sencilla, se despojaba a la muchacha del velo que le cubría el rostro y se depositaba éste sobre el hombro del novio. Acto seguido, el joven, escoltado por los amigos ${ }^{17}$, conducía a la muchacha, su ya esposa, al hogar conyugal (cfr. Mateo 25,6$)^{18}$. A continuación se organizaba un largo banquete nupcial ${ }^{19}$, en el que los invitados, portando sus mejores galas y atavíos ${ }^{20}$, degustaban un suculento ágape ${ }^{21}$ y disfrutaban de la ventura que suponía el surgimiento de una nueva familia (Proverbios 5, 18 ss.; Tobías 7, 10-13). No en vano, el primer milagro de Jesús ocurrió durante una boda celebrada en Caná de Galilea (Juan 2, 1-11), pues la boda se contemplaba, en idílica imagen ${ }^{22}$, como la «fiesta de la vida»: de la vida que empieza, de la vida que será transmitida, de la vida que se perpetuará con la prole.

«Para el hombre del pueblo — sintetiza a la perfección Papini-, que tan de raro en raro se expansiona y divierte, que no come ni bebe nunca todo cuanto quiere, el día de la boda es el más memorable de toda la vida. Un paréntesis de riqueza, de generosidad, de contento, en la larga y gris mediocridad de sus días. Los señores que todas las noches pueden banquetear, los modernos, que se tragan en un día lo que a un pobre antiguo le bastaba para una semana, no sienten la solemne alegría de ese día. Pero el pobre antiguo, el trabajador, el hombre de los campos, el oriental, que vivía todo el año con pan de cebada, higos secos, algún

le respondió: "Es mi señor". Ella agarró el velo y se cubrió. El siervo contó a Isaac cuanto había ocurrido, e Isaac condujo a Rebeca a la tienda de Sara, su madre; la tomó por mujer y la amó, consolándose de la muerte de su madre» (Sagrada Biblia, op. cit., pp. 28 y 29).

${ }^{17}$ Llevando antorchas en la mano y, con frecuencia, al son de la música y de la danza. Cfr. A. Millard et al., voz «Matrimonio», op. cit., p. 213.

18 Según indica W. R. F. BRowning (voz «Boda», op. cit., p. 78), los detalles de la parábola de las diez vírgenes (Evangelio de San Mateo 25, 1-13) son algo confusos. ¿La procesión se celebraba de noche? ¿Estaban abiertas más allá de la medianoche las tiendas que vendían aceite? (Mateo 25, 9).

${ }_{19}$ Mateo 22, 2-14. En estos versículos se habla, bien que se trate del banquete de bodas del hijo de un rey, de becerros y cebones. En lo que respecta a la bebida, en el Evangelio de Juan $(2,3)$ se alude al vino. Cfr. También Lucas $(14,7-11)$. Vid. R. BADEnAs, Para conocer al Maestro en sus parábolas, 1. ${ }^{a}$ ed., Safeliz, Madrid, junio de 2002, pp. 108-111.

${ }^{20}$ Mateo 22, 11-12.

${ }^{21}$ Los hebreos de la época bíblica tenían por costumbre comer sobre el suelo (no se utilizaba la mesa para este fin). Sólo más tarde, y gracias a la asimilación de las costumbres grecorromanas, empezaron a reclinarse sobre alfombras o almohadones. La comida se tomaba con la mano, pues, aunque se conocían los cubiertos, éstos se empleaban únicamente en los sacrificios. Cfr. E. Balasch Blanch e Y. Ruiz Arranz, voz «Comida», Diccionario Bíblico, Tikal Ediciones, Madrid, s.a., p. 106.

22 Vid. M. ${ }^{a}$ C. L. Bingemer, voz «Matrimonio», en J. J. TAmayo (dir.), Nuevo Diccionario de Teología, Trotta, Madrid, 2005, p. 575. 
pez que otro y tal cual huevo cocido, y únicamente en las grandes fiestas mataba un cordero o un cabrito; el hombre acostumbrado a penar, a medir, a pasarse sin tantas cosas, a contentarse con lo puramente necesario, veía en las bodas la fiesta más verdadera y grande de toda la vida. Las demás fiestas, las populares, las religiosas, eran de todos, iguales para todos. Y se repetían todos los años. Pero la boda era una fiesta completamente suya, solamente suya y no venía para él más que una vez en el curso de los años» ${ }^{23}$.

El matrimonio, por otro lado, no era una relación indisoluble por naturaleza (como la del hermano y la hermana) ${ }^{24}$, por lo que, bajo la ley mosaica, al marido le cabía repudiar a su esposa y celebrar, en su caso, nuevas nupcias con otra mujer (Deuteronomio 24, 1 ss.). El varón podía realizar el citado repudio si descubría en su cónyuge algún defecto o tara. Así, cuando la mujer no le agradaba ${ }^{25}$ «porque ha notado en ella algo de torpe, le escribirá el libelo de repudio ${ }^{26}$, y poniéndoselo en la mano, la mandará a su casa» ${ }^{27}$. En la época que siguió al exilio ${ }^{28}$, Esdras $(10,11)$ ordenó a los maridos repudiar a sus esposas extranjeras ${ }^{29}$. No obstante, ya en vida de Malaquías $^{30}(2,14$ ss.) estaba mal visto el divorcio, pues la unión matrimo-

${ }^{23}$ G. PAPINI, Historia de Cristo, Editorial Porrúa (trad.), Ediciones Folio, Barcelona, 2004, p. 124.

${ }_{24}$ Cfr. W. R. F. Browning, voz «Divorcio», op. cit., p. 140.

25 Bastaban razones ridículas para darle a una mujer «libelo de repudio», como no guisar bien. «Se atribuye — como sentencia J. GNILKA, Jesús de Nazaret. Mensaje e historia, versión castellana de C. Ruiz-GarRido, 2. ${ }^{a}$ ed., Herder, Barcelona, 1995, p. 272-al rabí Aqiba la declaración de que él repudiaría a su mujer si encontrara otra más guapa. Ciertamente, el marido estaba obligado a indemnizar financieramente a la repudiada».

${ }^{26} \mathrm{O}$ «certificado de divorcio». Cfr. J. Gnilka, Jesús de Nazaret..., op. cit., p. 272. Vid. asimismo http://buscon.rae.es/draeI/html/cabecera.htm.

27 Deutenonomio 24, 1. Cita extraída de Sagrada Biblia, op. cit., p. 233.

${ }^{28}$ Se narra en este libro de Esdras (y en el de Nehemías) la historia del pueblo israelita tras el cautiverio de Babilonia, cuando Ciro (rey de Persia) proclama en el año 538 a. C. un edicto que permite a los judíos retornar a Jerusalén. La fecha de redacción de estos dos libros (cuyo nombre está tomado de sus respectivos protagonistas principales: Esdras, escriba, y Nehemías, gobernador del rey persa) podría fijarse en tiempos de la dominación griega, hacia mediados del siglo iv a. C. Cfr. A. Fuentes Mendiola, Qué dice la Biblia. Guía para entender los Libros Sagrados, 2." ed., Ediciones Universidad de Navarra, Pamplona, enero de 2005, pp. 108 y 109.

${ }_{29}$ Cfr. J. R. Porter, La Biblia: las Sagradas Escrituras hebreas, los Libros Apócrifos, la llegada de Roma (Palestina en tiempos de Cristo) y el Nuevo Testamento, traducción y revisión de la edición en lengua española por M. Cavándoli, reimp., Blume, Barcelona, 2008, p. 117.

${ }^{30}$ El nombre de Malaquías proviene del hebreo mal'akî (mi mensajero). Debió de realizar su ministerio profético después del destierro, durante la dominación persa (siglo vI a. C.). Cfr. A. Fuentes Mendiola, Qué dice la Biblia..., op. cit., pp. 173 y 174. 
nial para toda la vida obraba como exacta analogía de la alianza ${ }^{31}$ sellada entre Dios y su pueblo ${ }^{32}$.

El marido perdía, sin embargo, este derecho de repudio si acusaba en falso a su esposa de intimidad carnal con otro varón. En el Deuteronomio $(22,13-19)$ se lee, en punto a ello: «Si un hombre, después de haber tomado mujer y haber entrado a ella, la aborreciere y le imputare falsamente delitos y la difamase, diciendo: "He tomado a ésta por mujer, y cuando a ella entré no la hallé virgen", el padre y la madre de ella tomarán las pruebas de su virginidad y las presentarán a los ancianos de la ciudad en las puertas. El padre de la joven dirá: "Yo he dado por mujer mi hija a este hombre, y él, habiéndola aborrecido, le imputa cosas deshonrosas, diciendo: No la he hallado virgen. Ahí están las pruebas de la virginidad de mi hija”, y desplegará la sábana ante los ancianos de la ciudad. Estos cogerán al hombre y le castigarán, le impondrán una multa de cien siclos ${ }^{33}$ de plata, que entregarán al padre de la joven, por haber esparcido la difamación de una virgen de Israel; tendrá que tomarla por mujer y nunca en la vida podrá repudiarla» ${ }^{34}$.

La situación preponderante del esposo se manifestaba básicamente en que él no podía quebrantar el propio matrimonio; sólo un matrimonio ajeno.

${ }^{31}$ La esencial alianza entre Dios y su pueblo se corporeiza en una metáfora que sacraliza la sexualidad: Israel será la esposa de Dios. Tan fuerte es la vinculación de la alianza con el matrimonio, que se emplea la misma palabra, berith, para designar a ambos. Cfr. al respecto J. ARIAS, La Biblia y sus secretos. Un viaje sin censuras al libro más vendido del mundo, 1. ${ }^{a}$ ed., Aguilar, Madrid, enero de 2004, p. 62, y J. L. CARAVIAS, Matrimonio y familia a la luz de la Biblia (1), en http://www.mercaba.org/FICHAS/BIBLIA/matrimonio_y familia_1.htm, p. 25.

${ }^{32}$ Oseas (siglo viII a. C.), hijo de Beeri y primero del grupo de los doce profetas menores (junto con Joel, Amós, Abdías, Jonás, Miqueas, Nahúm, Habacuc, Sofonías, Ageo, Zacarías y Malaquías), es pionero en emplear el lenguaje matrimonial para describir la comunidad de amor entre Yahvé y su grey (cfr. Oseas 2, 16-25). Cuando Oseas se ve traicionado por su mujer (Gomer), una prostituta, sigue amando a ésta. Se percata entonces el profeta de que Dios también continúa amando al pueblo elegido a pesar de sus infidelidades (cfr. Oseas 3, 1). Vid. M. ${ }^{a}$ C. L. Bingemer, voz «Matrimonio», op. cit., pp. 573-575. Cfr. también H. TADMOR, en H. H. Ben-SASSON (dir.), Historia del pueblo judío, 1, Desde los orígenes hasta la Edad Media, versión española de M. CALÉs, Alianza Editorial, Madrid, 1988, p. 217; J. W. Rogerson, Una introducción a la Biblia, M. ${ }^{a}$ del C. Blanco Moreno y R. A. Díez Aragón (trads.), Ediciones Paidós Ibérica, Barcelona, 2000, p. 83; A. SARmienTo, voz «Matrimonio», op. cit., pp. 632 y 633; La Biblia de Juan Pablo II. Los fragmentos bíblicos más amados por el Papa que inspiraron sus reflexiones y plegarias, I. Prieto (trad.), 1. ${ }^{\text {a }}$ ed., La Esfera de los Libros, Madrid, noviembre de 2008, pp. 145-147.

33 En tiempos del Antiguo Testamento, el siclo era una unidad de peso, equivalente a unos once gramos y medio de plata. En la época del Nuevo Testamento se transformó en una moneda de plata del mismo peso. Cfr. W. R. F. Browning, voz «Siclo», op. cit., p. 422.

${ }^{34}$ Cita tomada de Sagrada Biblia, op. cit., pp. 231 y 232. 
Cual constata Gnilka, «las relaciones sexuales con personas solteras no se consideraban adulterinas sino en el caso de la mujer, nunca en el caso del marido. Esta mentalidad jurídica se basaba en la idea de que la mujer era propiedad del marido y que, por tanto, el hombre que invadía un matrimonio ajeno cometía un delito contra la propiedad ${ }^{35}$ (privada) de otro» ${ }^{36}$.

Ya en el Nuevo Testamento, preguntado Jesús por los fariseos ${ }^{37}$ acerca de su posición sobre el repudio de la mujer — tal y como se relata en el Evangelio de San Marcos (10, 2-12)—, respondió: «¿Qué os ha mandado Moisés? Contestaron ellos: "Moisés manda escribir el libelo de repudio y despedirla". Díjoles Jesús: "Por la dureza de vuestro corazón os dio Moisés esta ley; pero al principio de la creación los hizo Dios varón y hembra; por esto dejará el hombre a su padre y a su madre, y serán los dos una sola carne ${ }^{38}$. De manera que no son dos, sino una sola carne ${ }^{39}$. Lo que Dios juntó, no lo separe el hombre". Vueltos a casa, de nuevo le preguntaron sobre esto los discípulos, y les dijo: "El que repudia a su mujer y se casa con otra, adultera contra aquélla, y si la mujer repudia al marido y se casa con otro, comete adulterio" $\gg^{40}$. En el Evangelio de San Mateo $(19,9)$,

${ }^{35}$ Cfr. J. Arias, La Biblia..., op. cit., p. 61.

36 J. GnILKA, Jesús de Nazaret..., op. cit., p. 272.

37 Nombre que proviene del hebreo perûsim (los separados). Se dedicaban en tiempos de Jesús al estudio de la Torá (Ley) y de las tradiciones (Misná). Eran laicos, enfrentados a la aristocracia sacerdotal compuesta por los saduceos. Interpretaban rígidamente la ley, en especial en lo relativo al sábado, a la pureza ritual y a los diezmos. Cfr. A. Fuentes Mendiola, Qué dice la Biblia..., op. cit., pp. 318 y 319; J. Klausner, Jesús de Nazaret..., op. cit., pp. 252 y 263-269, y F. VARO, 50 preguntas sobre Jesús, J. ChAPA (ed.), Rialp, Madrid, 2006, pp. 57 y 58 .

${ }_{38}$ Cfr. Génesis 2, 24.

39 Señala Bingemer (voz «Matrimonio», op. cit., pp. 575 y 576) al hilo de ello: «Para entender qué significa contraer matrimonio a la luz del Señor y de la Buena Noticia, hay que mirar el corazón de la enseñanza de Jesús como un todo. Jesús nos dejó el mandamiento del amor (Juan 13, 34): amarnos como él nos amó; hasta el amor a los enemigos (Mateo 5, 44); hasta la entrega de la vida (Filipenses 2, 6-11). El mandamiento del amor lo dirige a todos sus seguidores. Es el centro y el resumen de su mensaje. Y ha de ser también la médula de todo matrimonio que verdaderamente quiera ser parte del seguimiento de Jesús. Quien desee ubicar el matrimonio en un marco bíblico debe situarlo, pues, en el plano del amor. Dios creó al ser humano varón y mujer, a su imagen. Por eso, el matrimonio, al margen de cualquier formulismo o rito, ha de fundamentarse, ante todo, en el amor, ya que dios es amor».

${ }_{40}$ Sagrada Biblia, op. cit., p. 1.286. Jesús —explana A. E. J. Rawlinson, The Gospel according to St. Mark, Westminster Commentaries, Methuen, Londres, 1925, p. 134- deduce del Génesis el ideal del matrimonio permanente e indisoluble. Cfr. igualmente J. KLAusNER, Jesús de Nazaret..., op. cit., p. 464.

Jesús —señalarán G. TheIssen y A. Merz, El Jesús histórico. Manual, M. Olasagasti (trad.), 3. ${ }^{a}$ ed., Sígueme, Salamanca, 2004, p. 415- «aboga por la indisolubilidad del matrimonio (Marcos 10, 2 ss.), ve ya realizado el adulterio en el deseo sexual (Mateo 5, 27 ss.) 
Jesús, como excepción, permite que el marido repudie a la mujer si ésta incurre en adulterio ${ }^{41}$. Un Jesús que abroga sin circunloquios, ahora en el Evangelio de Juan (8, 1-11), la ley del Deuteronomio (22, 23-24) que prescribía la lapidación como pena para una virgen prometida sorprendida en flagrante adulterio. Al afirmar que sólo pueden arrojar piedras los que se encuentren ayunos de pecado, declara inejecutable la sentencia mosaica ${ }^{42}$.

Aunque el «acta de divorcio» — conforme postula Browning ${ }^{43}$ - presumiblemente necesitaba de la presencia de una autoridad, existía empero la posibilidad de un procedimiento de carácter privado, que es el que en principio quiso utilizar San José cuando le fue revelado que su prometida, la Virgen María, estaba encinta (Mateo 1, 19) ${ }^{44}$.

La concubina era la esposa secundaria, a la que la ley hebrea concedía ciertos derechos mínimos (Deuteronomio 21, 15-17). Sara y Raquel, padeciendo de infecundidad, entregaron sus respectivas criadas (la egipcia Agar y Bala) a sus maridos (Abraham y Jacob) al intento de que éstos pudieran tener descendencia ${ }^{45}$ (Génesis 16, 1-3; 30, 3-6). Y cosa similar hizo Lía (que dio a su esclava Zelfa a Jacob), bien que ella no sufría esterilidad (Génesis 30, 9). Los monarcas Saúl (2 Samuel 3, 7) y David (2 Samuel 5,13) tomaron concubinas, y cuando Absalón yació públicamente con las concubinas de su progenitor estaba haciendo reivindicación

y elogia, en el dicho sobre los eunucos, la renuncia a la sexualidad por el Reino de Dios (Mateo 19, 12)». Cfr., asimismo, J. L. MarTín Descalzo, Vida y misterio de Jesús de Nazaret,

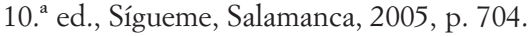

${ }^{41}$ Cfr. también Mateo $(5,32)$. Vid. A. Sarmiento, voz «Matrimonio», op. cit., pp. 636 y 637.

42 J. W. RogERSON, Una introducción..., op. cit., p. 219.

43 W. R. F. BRownING, voz «Divorcio», op. cit., p. 140.

${ }^{44}$ El Evangelio de San Mateo $(1,18-24)$ cuenta lo siguiente: «La concepción de Jesucristo fue así: estando desposada María, su madre, con José, antes de que conviviesen se halló haber concebido María del Espíritu Santo. José, su esposo, siendo justo, no quiso denunciarla y resolvió repudiarla en secreto. Mientras reflexionaba sobre esto, he aquí que se le apareció en sueños un ángel del Señor y le dijo: José, hijo de David, no temas recibir en tu casa a María, tu esposa, pues lo concebido en ella es obra del Espíritu Santo. Dará a luz un hijo, a quien pondrás por nombre Jesús, porque salvará a su pueblo de sus pecados [...] Al despertar José de su sueño hizo como el ángel de Señor le había mandado, recibiendo en casa a su esposa, la cual, sin que él antes la conociese, dio a luz un hijo y le puso por nombre Jesús» (cita tomada de Sagrada Biblia, op. cit., p. 1229).

${ }^{45}$ Según explica con perspicuidad H. A. MerTens (Manual de la Biblia. Aspectos literarios, históricos, arqueológicos, histórico-religiosos, culturales y geográficos del Antiguo y Nuevo Testamento, versión castellana de C. GANCHO, Herder, Barcelona, 1989, p. 164), «una mujer casada sin hijos podía, en efecto, solicitar de su marido que tomara como esposa segunda a alguna esclava concubina; si esa esclava tenía hijos, esos niños eran considerados jurídicamente como hijos de la señora o esposa principal. Y tan hijos suyos eran que los hijos de la esclava borraban el oprobio de la señora que no podía tener descendencia». 
de su estatus regio. También Salomón contó con una nutrida lista de concubinas $^{46}$, que ascendían a trescientas (1 Reyes 11,3$)$.

El Libro de Ezequiel $(16,4)$ refleja que, luego de lavar al recién nacido, se tenía la costumbre de purificarlo frotándolo con sal ${ }^{47}$. La madre de hijo varón (al que se circuncidaba al octavo día de ver la luz) quedaba ritualmente impura durante los siete días posteriores al parto, en el que asistía a la mujer una comadrona (Éxodo 1, 15-17) ${ }^{48}$; y, además, durante un total de cuarenta días (tras el alumbramiento) se le prohibía entrar en un santuario o tocar cualquier cosa sagrada. En el caso de que el bebé fuera niña, la duración del tiempo requerido para la purificación se duplicaba (Levítico 12, 5) ${ }^{49}$. Cumplidos tales días de purificación, la mujer presentaba «ante el sacerdote, a la entrada del tabernáculo de la reunión, un cordero primal en holocausto y un pichón o una tórtola en sacrificio» ${ }^{50}$. Completando esta cuestión ceremonial, el Génesis $(21,8 \mathrm{ss} .)^{51}$ habla de la fiesta que se organizaba para celebrar el destete de los niños, que tenía lugar por lo general a los tres años de edad ${ }^{52}$.

Solía corresponderle a la madre elegir el nombre del hijo (1 Samuel 1, $20)^{53}$, pero era el padre quien proporcionaba instrucción religiosa y prácti-

${ }^{46}$ Amén de setecientas mujeres de sangre real.

47 «Y, quizá, de ahí — apostilla ARIAS (La Biblia..., op. cit., p. 169) — proceda la costumbre de colocar una pizca de sal en la boca del niño cuando se oficia el sacramento del bautismo».

48 «Ordenó el rey de Egipto a las parteras de los hebreos, de las cuales una se llamaba Sifrá y la otra Fuá, diciéndoles: "Cuando asistáis al parto a las hebreas, observad el sexo: si es niño, lo matáis; si niña, que viva”. Pero las parteras eran temerosas de Dios y no hacían lo que les había mandado el rey de Egipto, sino que dejaban con vida a los niños» (cita tomada de Sagrada Biblia, op. cit., p. 64).

49 «Al fin -comentará M. Douglas, El Levítico como literatura. Una investigación antropológica y literaria de los ritos en el Antiguo Testamento, J. Arrambide y M. Pino Moreno (trads.), 1. ${ }^{\text {a }}$ ed., Gedisa, Barcelona, mayo de 2006, p. 208-, la incapacidad ritual no es una penuria: en realidad la mujer necesita el privilegio del descanso. El hijo debe ser apartado de la madre para el rito de la circuncisión a los ocho días del nacimiento, pero el aislamiento de la madre debe mantenerse durante cuarenta días. En el caso del nacimiento de una hija, el Levítico duplica el periodo de reclusión, que de ese modo asciende a ochenta días. Gracias a la circuncisión, el hijo varón se convierte en parte del pacto sellado por Abraham, de una manera que jamás será posible para una niña. Resulta interesante que él no se contagie de la impureza por contacto cuando se devuelve a su madre para que ésta lo amamante. Casi con toda seguridad, el rito de la circuncisión ejercía efectos profilácticos tanto sobre la madre como sobre el niño. Ésa era una de las razones por las que se duplicaba el periodo de impureza de la madre que había dado a luz a una niña».

${ }^{50}$ Levítico 12, 6. Cita tomada de Sagrada Biblia, op. cit., p. 128.

${ }^{51}$ Se refiere al destete de Isaac (hijo de Abraham y Sara), con ocasión del cual su padre organizó un gran banquete.

52 Cfr. E. Balasch Blanch e Y. Ruiz Arranz, voz «Destete», op. cit., p. 119.

53 Dentro de las familias, las mujeres — que tenían la sagrada misión de ser fuente de la vida- eran las grandes responsables de la educación de los hijos. Cfr. J. ARIAS, La Biblia..., op. cit., pp. 68 y 72 . 
ca al vástago (Éxodo 10, 2; Eclesiástico 30, 1-13), inculcándole el amor al trabajo y el esfuerzo para lograr la sabiduría, todo ello bajo un régimen de estricta disciplina (Proverbios 13, 24).

La familia hebrea tenía la singularidad de constituir por sí sola un centro de culto en el que el padre desempeñaba labores de sacerdote ${ }^{54}$. El marido ostentaba la jefatura de la familia ${ }^{55}$ y se erigía en su cabeza visible. La mujer estaba sujeta al esposo ${ }^{56}$, a quien debía reverencia y sumisión, y éste había de amar a aquélla como a su propio cuerpo (Epístola de San Pablo a los Efesios 5, 22-33; Epístola 1 de San Pedro 3, 7). El hijo, por su parte, había de honrar al padre ${ }^{57}$ y respetar a la madre (Eclesiástico 3, 3-7 y 14-17) $)^{58}$.

\footnotetext{
${ }^{54}$ La madre acometía las tareas domésticas, pero su peso en la familia aumentaba conforme crecía el número de hijos. Cfr. E. Balasch Blanch e Y. Ruiz ArRanz, voz «Familia», op. cit., p. 161.

${ }^{55} \mathrm{Y}$, tras su muerte, al primogénito. Cfr. Génesis 27, 29.

56 El Libro de los Proverbios acaba con un poema acróstico —en el que cada verso comienza por una de las letras del alefato hebreo tomadas por su orden- que ensalza a la esposa perfecta $(31,10-31)$ : «Alef: La mujer fuerte, ¿quién la hallará? Vale mucho más que las perlas. Bet: En ella confía el corazón de su marido, y no carece de ganancia. Guímel: Proporciónale ventura, no desgracia, todo el tiempo de su vida. Dálet: Ella se procura lana y vino y hacen las labores con agrado sus manos. He: Es como nave de mercader, que desde lejos se trae su pan. Wau: Todavía de noche se levanta y distribuye a su familia la pitanza, y da órdenes a sus criadas. Zain: Cavila sobre un campo y lo compra, y con el fruto de sus manos planta una viña. Jet: Ciñe con vigor sus lomos y fortalece sus brazos. Tet: Experimenta que es buena su ganancia, y ni de noche apaga su lámpara. Yod: Tiende sus manos a la rueca, y sus palmas agarran el huso. Caf: Tiende sus palmas al desvalido y alarga la mano al menesteroso. Lámed: No teme su familia la nieve, porque todos en su casa tienen vestidos dobles. Mem: Ella se hace cobertores, y sus vestidos son lino y púrpura. Nun: Conocido es en las puertas su marido cuando se sienta entre los ancianos del país. Sámec: Hace una túnica y la vende, entrega al mercader un ceñidor. Ayin: Se reviste de fortaleza y de dignidad y sonríe ante el porvenir. Pe: Con sabiduría abre su boca, y en su lengua está la ley de la bondad. Sade: Vigila la marcha de su casa y no come su pan de balde. Qof: Álzanse sus hijos y la aclaman bienaventurada, y su marido la ensalza. Res: "Muchas hijas han hecho proezas, pero tú a todas sobrepasas". Sin: Engañosa es la gracia, vana la belleza; la mujer que teme a Dios, ésa es de alabar. Tau: Dadle del fruto de sus manos y alábenla sus obras en las puertas» (tomado de Sagrada Biblia, op. cit., pp. 845 y 846).

57 «"Honra a tu padre y a tu madre: así se prolongarán tus días en la tierra, que el Señor, tu Dios, te va a dar". Así reza el cuarto mandamiento en la versión del Libro del Éxodo (20, 12). El precepto va dirigido a los hijos y habla de los padres; refuerza, por tanto, la relación entre generaciones y la comunión de la familia como un orden querido y protegido por Dios. Habla del país y de la continuidad de la vida en el país, es decir, establece una relación estrecha entre el país, como espacio vital del pueblo, y el orden fundamental de la familia, y vincula la existencia de pueblo y de país a la comunión de generaciones que se crea en la estructura familiar», BENEDICTO XVI, Jesús de Nazaret, primera parte (Desde el Bautismo a la Transfiguración), C. Bas Álvarez (trad.), 1. ${ }^{a}$ ed., La Esfera de los Libros, Madrid, septiembre de 2007, p. 144.

58 «Pues Dios honra al padre en los hijos y confirma en ellos el juicio de la madre. El que honra al padre expía sus pecados. Y como el que atesora es el que honra a su madre. El que honra a su padre se regocijará en sus hijos y será escuchado en el día de su oración. El que honra a su padre tendrá larga vida [...] Hijo, acoge a tu padre en su ancianidad y no le
} 
El primogénito gozaba de privilegios especiales en cuestión de herencia ${ }^{59}$ (el padre debía darle «de sus bienes dos tantos»: Deuteronomio 21, $17)^{60}$. Se creía que el primer hijo varón de una familia y la primera cría macho de un animal (es decir, las primicias del seno materno) estaban consagrados a Dios (para garantizar una bendición sobre el resto de la familia o del rebaño), por lo que, a fin de evitar su sacrificio, debían ser redimidos (Éxodo 13, 1 y 11-16) ${ }^{61}$. Repárese también en que la última de las plagas infligidas a Egipto fue, por la importancia de éstos, la muerte de los primogénitos de sus hombres y animales ${ }^{62}$.

Los huérfanos y las viudas ${ }^{63}$ eran los miembros más menesterosos y vulnerables de la sociedad, tanto en la época del Antiguo Testamento como durante el Nuevo. Se exhortaba a los hebreos a atender y cuidar de unos y otras (Éxodo 22, 22; Epístola de Santiago 1, 27), y Dios velaba especialmente por ellos y les hacía justicia (Deuteronomio 10, 18; Salmos 146,9 y 68,6$)^{64}$. Se dirigían también los huérfanos a los reyes en solicitud de apoyo y amparo (Salmo 72, 1-4-12-14), pero con frecuencia sus súplicas no obtenían sino desaires (Jeremías 5, 28).

Las viudas ${ }^{65}$, que estaban tremendamente desprotegidas en la sociedad patriarcal, debían vestirse con ropas austeras. Si carecían de hijos y no

des pesares en su vida. Si llega a perder la razón, muéstrate con él indulgente y no le afrentes porque estés tú en la plenitud de tu fuerza; que la piedad con el padre no será echada en olvido. Y en vez del castigo por los pecados tendrás prosperidad. En el día de la tribulación, el Señor se acordará de ti, y como se derrite el hielo en día templado, así se derretirán tus pecados» (Sagrada Biblia, op. cit., p. 886).

59 «Era por tanto a Esaú — hijo mayor de Isaac y Rebeca—, y no a Jacob — su hermano gemelo_- a quien en justicia correspondía el derecho de primogenitura — pero aquél le cedió este derecho a Jacob a cambio de un plato de lentejas (Génesis 25, 29-34) - y la bendición del padre» (Génesis 27, 1-40). Cfr. también Lucas 15, 31.

60 Sagrada Biblia, op. cit., p. 230. No obstante, una hija podía heredar también (Job 42, 15), siempre y cuando no se casara fuera de la tribu (Números 27, 1-8). Si no había hijos, el hermano del fallecido entraba en posesión de la herencia. Cfr. W. R. F. BRowning, voz «Heredero(s)», op. cit., p. 216.

${ }_{61}$ Cfr., asimismo, 2 Reyes 3, 27.

${ }^{62}$ Cfr. Éxodo 13, 15. Vid. al respecto R. Beretta y E. Broli, Enigmas de la Biblia..., op. cit., pp. 53-57.

63 Cfr. C. Markschies, Estructuras del cristianismo antiguo. Un viaje entre mundos, J. A. Padilla Villate (trad.), 1. ${ }^{\text {a }}$ ed. en castellano, Siglo XXI, Madrid, enero de 2001, pp. 129 y 215 .

${ }^{64}$ Ezequiel $(22,7)$ reprende a quienes no se ocupan como debieran de huérfanos y viudas.

${ }^{65}$ De acuerdo con J. G. Frazer [El folklore en el Antiguo Testamento, G. Novas (trad.), Fondo de Cultura Económica, Madrid, 1. ${ }^{a}$ reimp. en España de la 1. ${ }^{a}$ ed. en español, 1993, pp. 460 y 461], «la palabra hebrea que se traduce por "viuda" (alemanab) se halla posiblemente relacionada con un adjetivo que significa "mudo" (illem). Si esa etimología es correcta, vendría a resultar que los hebreos llamaban a las viudas "mujeres que no hablan”. ¿Qué 
podían contraer matrimonio por levirato, regresaban a la casa paterna. En cambio, si tenían hijos, quedaban al cuidado de los mismos ${ }^{66}$. Los profetas del Antiguo Testamento apelaron a menudo a la conciencia de la nación en provecho de ellas $(v$. gr., Isaías 1, 23), mientras que los apóstoles se encargarán con denuedo de organizar la distribución de las limosnas para tales mujeres (Hechos 6, 1 ss.). Pablo, aunque sin demasiado entusiasmo al respecto, admitía que las viudas casaderas, si se les presentaba la oportunidad, pudieran contraer nuevo matrimonio (1 Corintios 7,40$)^{67}$.

En el marco del matrimonio, destaca también la mencionada institución del levirato, relacionada con la figura del go'el (el que protege o rescata), un antiguo término técnico que designaba a la persona (de ordinario, el pariente más próximo) que dentro del clan asumía la obligación de velar por los intereses del individuo o del grupo familiar ${ }^{68}$, ya rescatando o manteniendo un patrimonio familiar (Levítico 25, 23-28), ya reintegrando a su familia a su estatus social en el supuesto de que ella o uno de sus componentes hubiera caído en esclavitud (Levítico 25, 47-53), ya protegiendo a una viuda (Rut 3, 9-13; 4, 5-7), o vengando a un pariente asesinado (Números 35, 12-32; Deuteronomio 19, 6-12).

Según dicha institución del levirato (de levir, cuñado) — codificada en el veterotestamentario texto del Deuteronomio (25, 5-10)-, a la mujer que enviudaba sin haber tenido hijos podía darle sucesión el hermano de su difunto marido ${ }^{69}$ mediante un segundo matrimonio. Y el primogénito de este nuevo matrimonio endogámico era reconocido legalmente como hijo del finado a todos los efectos ${ }^{70}$. Ciertamente, tal deber jurídico-moral ${ }^{71}$ de suscitar prole en la viuda no obligaba en un sentido absoluto, mas el incumplimiento del mismo se tenía por una falta de honor (una suerte de acto infame o ignominioso) entre los judíos ${ }^{72}$. La ley del levira-

motivos habría para llamar mujer que no habla a una viuda? Yo me imagino, con todas las reservas debidas, que el epíteto puede ser explicado mediante una costumbre muy extendida que impone por algún tiempo a una viuda la obligación de guardar silencio absoluto tras la muerte de su marido. A veces la obligación abarca un periodo de tiempo considerable».

${ }^{66}$ Cfr. E. Balasch Blanch e Y. Ruiz Arranz, voz «Viuda», op. cit., p. 345.

${ }^{67}$ Cfr. también el propio San Pablo (Epístola 1 a Timoteo 5, 11-14).

${ }^{68}$ Cfr. M. Á. TÁBET, Introducción al Antiguo Testamento, I, Pentateuco y Libros Históricos, A. Esquivias Villalobos (trad.), Pelícano, Madrid, 2004, pp. 409 y 410.

${ }^{69} \mathrm{Al}$ levirato se le denomina también «matrimonio entre cuñados». Cfr. A. OHLER, Atlas de la Biblia, J. Chamorro Mielke (trad.), Akal, Madrid, 2009, p. 133.

${ }^{70}$ Cfr. A. Fuentes Mendiola, Qué dice la Biblia..., op. cit., p. 320.

${ }^{71}$ Cfr. M. Á. TÁBET, Introducción..., op. cit., p. 411.

72 Así lo recoge la citada norma del Deuteronomio (25, 5-10): «Cuando dos hermanos habitan uno junto al otro y uno de los dos muere sin dejar hijos, la mujer del muerto no se 
to alcanzaba, en principio, a todos los hermanos que estuvieran aún vivos (Mateo 22, 24-28) ${ }^{73}$, pero no a parientes en un sentido más amplio ${ }^{74}$. El Libro de Rut, sin embargo, parece suponer que el deber pesaba asimismo sobre los parientes más lejanos $(3,12-13)^{75}$. Con esta práctica se trataba de evitar la extinción de una familia, situación considerada en Israel como un grave e insoportable quebranto (2 Samuel 14, 7).

casará fuera con un extraño; su cuñado irá a ella y la tomará por mujer, y el primogénito que de ella tenga llevará el nombre del hermano muerto, para que su nombre no desaparezca de Israel. Si el hermano se negase a tomar por mujer a su cuñada, subirá ésta a la puerta, a los ancianos, y les dirá: "Mi cuñado se niega a suscitar en Israel el nombre de su hermano; no quiere cumplir su obligación de cuñado, tomándome por mujer". Los ancianos de la ciudad le harán venir y le hablarán. Si persiste en la negativa y dice: "No me agrada tomarla por mujer", su cuñada se acercará a él en presencia de los ancianos, le quitará del pie un zapato y le escupirá en la cara, diciendo: "Esto se hace con el hombre que no sostiene la casa de su hermano". Y su casa será llamada en Israel la casa del descalzado» (Sagrada Biblia, op. cit., pp. 234 y 235$)$.

73 Cfr. también Mateo (22, 23-30), en el que se da cuenta del diálogo, a propósito del levirato, entre Jesús y los saduceos (una de las principales sectas del judaísmo al inicio de nuestra era. Enemigos de los fariseos, estaban apoyados por la aristocracia y el alto clero. Si bien creían en la existencia de Dios, negaban la existencia de los ángeles o la resurrección). Vid. también J. Klausner, Jesús de Nazaret..., op. cit., pp. 253 y 269-283.

${ }^{74}$ Esta ley tiene manifiesta aplicación en la historia de Tamar, casada con Er, primogénito de Judá. Quedando ella viuda sin descendencia, casóse después con su cuñado Onán, quien también falleció sin darle hijos. Como Judá no quiso entonces, vulnerando la ley del levirato, que otro de sus hijos (Sela) se uniera también en matrimonio a Tamar, ésta decidió idear un ardid: disfrazándose de prostituta yació con Judá, y alumbró a dos gemelos, Fares y Zaraj. Cfr. Génesis 38.

${ }^{75}$ Se trata — según recuerda M. Á. TÁBET, Introducción..., op. cit., p. 412- del único caso conocido del Antiguo Testamento, y no existen otros ejemplos que orienten en este sentido. 